\title{
Numerical verification of the correctness of the modelling clutch with adjustable torsional
}

\author{
Numeryczna weryfikacja poprawności modelowania sprzęgła \\ z regulowaną podatnością skrętną
}

\section{MAREK BORYGA PAWEK KOŁODZIEJ *}

Construction, principles and results of stress analysis and modal analysis of the clutch components with adjustable torsional flexibility are presented. Solid models of individual elements, geometric relations between them, stress analysis and modal analysis were made using the Autodesk Inventor program. Results of the analysis confirm the correctness of the clutch construction in terms of mechanical properties. KEYWORDS: flexibility clutch, adjustable torsional flexibility, stress analysis, modal analysis, finite element method

The course of work related to the design and implementation for the production of a new technical facility can be presented in the form of a block diagram (fig. 1).

A characteristic feature of such a method of proceeding is the ability to check the correctness of a construction solution before the prototype is created, based on modeling and simulation. There are many computer-aided design systems that, in addition to creating $2 \mathrm{D}$ and $3 \mathrm{D}$ documentation, allow you to enter loads, define materials and perform numerical calculations. One of them is Autodesk Inventor, where stress and strain analysis as well as modal analysis can be performed on the same model.

The authors of the work [4] on the basis of the results of the modal analysis of a lightweight racing car body increased the rigidity of the frame, improving the stability of the vehicle on road unevenness. In the work [7] the methodology of testing a selected part of the port crane was presented. The tests confirmed the usefulness of Inventor software to recognize degradation in crane construction elements. In paper [2] the authors presented the principle of operation, characteristics and analysis of the compression of flexible coupling elements with the possibility of stepless adjustment of torsional stiffness. The tests confirmed the correctness of the clutch structure in terms of durability.

In some publications, the initial assessment of the effectiveness of the designed subassembly has been preceded by analytical dynamic calculations. In practice [1], examples of improper and correct selection of the flexible coupling in the drive system are presented. The first method uses the coefficient of coupling $K$, while in the second detailed dynamic calculations. The authors stated that

\footnotetext{
* Dr hab. inż. Marek Boryga (marek.boryga@up.lublin.pl), dr inż. Paweł Kołodziej (pawel.kolodziej@up.lublin.pl) - Uniwersytet Przyrodniczy w Lublinie
}

a properly selected coupling is susceptible to a simple and relatively inexpensive way of reducing the amplitude of twisted vibrations and the additional dynamic load on the components of the drive system.

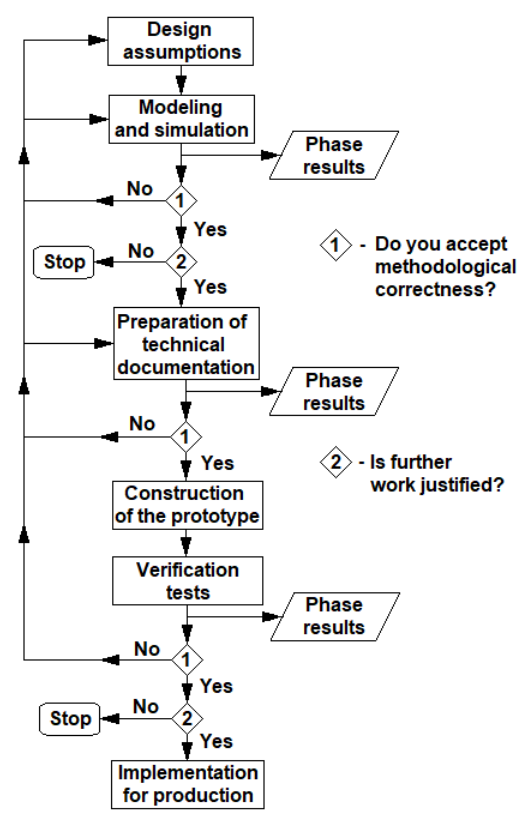

Fig. 1. Diagram of the design and implementation process for production

The paper [3] presents the frequency analysis of the flexible coupling, enabling the change of torsional stiffness. The influence of stiffness changes in the designed coupling on the amplitude of forced steady-state vibrations was determined. The vibration parameters for selected values of the torsional stiffness coefficient were calculated at the excitation forces close to the natural frequency and after the stiffness change.

The aim of this work is to present the structure, principles of operation and the results of stress analysis and modal analysis of selected elements of a new coupling construction with variable torsional susceptibility [5]. The Autodesk Inventor Professional program was used, allowing modeling of the clutch elements, assembling them into a set, determining the distribution of stresses and strains, and the frequency of natural vibrations. 


\section{Construction and operation principle of the clutch with variable torsional susceptibility}

Fig. 2 shows a flexible coupling that allows adjustment of torsional stiffness. The clutch is constructed of a hollow input shaft 1 connected to the active disk 2. A stepper motor 3 is built inside the shaft, which drives the spline shaft 4 and the control disk 5 mounted on it. Symmetrically three spiral guide channels are made in the disk, the surfaces of which cooperate with three spring bolts 6 . A control disc is provided between the inner 7 and outer 8 support plates. In each of the thrust plates connected by means of six pins 9 , three sloped guide channels are made. In the channels, the same sliders 10 are arranged to fix the position of the spring bolts 6 . The bolts 6 cooperate with both the sliders 10 and flat U-shaped springs 11 , the ends of which are mounted in the holders of the active disk 2 and secured against slipping with pins 12. For the outer stop disk 8 is attached to the output shaft 13 .

a)

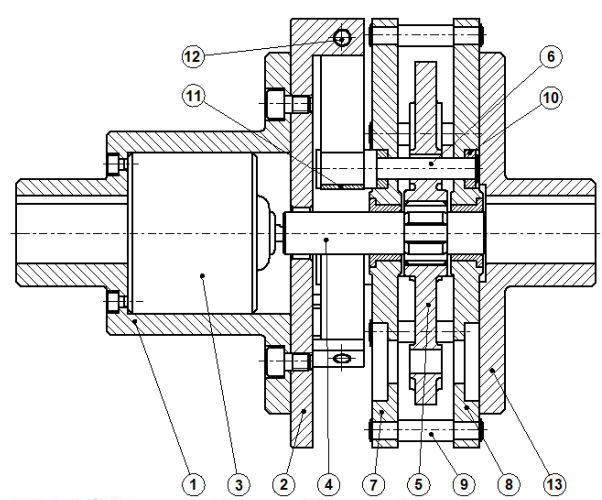

b)

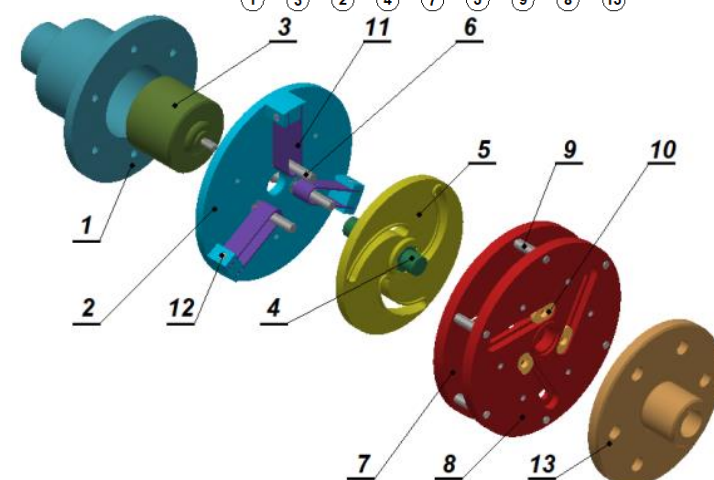

Fig. 2. Coupling construction with adjustable torsional susceptibility: a) clutch section, $b$ ) "exploding" drawing

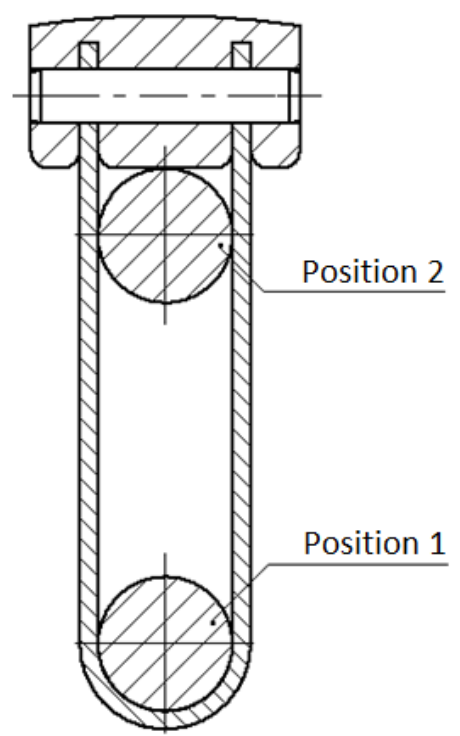

Fig. 3. Cross-section of the spring and pin in two extreme positions
The transmission of the torque from the active part (input shaft 1 , active disk 2) to the passive part (internal resistance plate 7 , pins 9 , outer stop disk 8 , output shaft 13 ) is effected by means of three spring shaped of a letter $U 11$. The susceptibility adjustment is the effect of changing the active length of the springs due to the radial displacement of the spring bolts 6 during the rotation of the control disk 5 . The maximum flexibility of the coupling is obtained when the spring bolts 6 are closest to the free ends of the springs 11 (position 1), while the minimum - when the pins 6 are closest to the spring set 11 (position 2).

Fig. 3 shows the method of fixing the spring and the position 1 and 2 of the pin.

\section{Results of the numerical analysis}

The analysis takes into account the components of the torque transfer coupling, and the operation of the units whose task is to control the change in flexibility (stepper motor, control disc shaft, control disc) is omitted. The input disc was loaded with a static moment $M=5 \mathrm{~N} \cdot \mathrm{m}$, while the initial disc was fixed, while the surface of the bolt holes used to fix the output shaft was selected as a static.

Materials that have naming and strength properties are included in the Inventor database, as well as material defined and added to the base - spring steel. The table lists the mechanical properties and the designation of standardized materials.

TABLE. Mechanical properties of materials
\begin{tabular}{|l|l|l|c|c|c|}
\hline Element & $\begin{array}{c}\text { Material from } \\
\text { the Inventor } \\
\text { database }\end{array}$ & $\begin{array}{r}\text { Real mate } \\
\text { rial }\end{array}$ & $\begin{array}{c}\text { Poisson's } \\
\text { number } \\
v\end{array}$ & $\begin{array}{c}\text { Young's } \\
\text { modulus } \\
E, \\
\text { GPa }\end{array}$ & $\begin{array}{c}\text { Limit of } \\
\text { plasticity } \\
R_{e}, \\
\text { MPa }\end{array}$ \\
\hline $\begin{array}{l}\text { Input disc, } \\
\text { thrust disc }\end{array}$ & $\begin{array}{l}\text { Non-alloy } \\
\text { steel }\end{array}$ & $\begin{array}{l}\text { S275J0 } \\
\text { S275J2G3 }\end{array}$ & 0.30 & 210 & 250 \\
\hline $\begin{array}{l}\text { Spring pin, } \\
\text { thrust disc } \\
\text { pin }\end{array}$ & Soft steel & S235JR & 0.28 & 220 & 207 \\
\hline $\begin{array}{l}\text { Slider of the } \\
\text { thrust disc, } \\
\text { spring bolt }\end{array}$ & Carbon steel & $\begin{array}{l}\text { C25 } \\
\text { C35 }\end{array}$ & 0.29 & 200 & 350 \\
\hline Spring & Spring steel & $51 \mathrm{CrV4}$ & 0.29 & 200 & 1080 \\
\hline
\end{tabular}

Initially, automatic contacts were generated. Connected for all clutch elements, and then selected contacts were manually modified to ensure the correct interaction of parts in the assembly [6].

Two changes have been made to the standard settings in the mesh settings. The Average Element Size was set to 0.08 , while the Maximum turn angle was assumed to be $30^{\circ}$. In addition, the Create Curved Mesh Elements option and Use part based measure for Assembly mesh are checked. The Mesh Settings window is shown in fig. 4.

Changes in convergence settings have also been introduced [6]. The Maximum number of $h$ Refinements is assumed - six - and the Stop Criteria - $2 \%$. This means that the program performs calculations up to six times, modifying the mesh in places where maximum stress is present, until the difference in results in subsequent repeats does not exceed $2 \%$. The Convergence Settings window is shown in fig. 5 .

Stress analysis was performed for the two extreme positions of the control disc. In position 1, the system generated a mesh in which the number of elements was 145,017 , while the number of nodes $-243,487$ (fig. 6 a). In position 2 the number of elements was 140,930 , while the number of nodes $-236,039$ (fig. $6 b$ ).

Figs. 7-9 present the distribution of reduced stresses, calculated according to the Huber-Mises-Hencky hypothesis $(\mathrm{H}-\mathrm{M}-\mathrm{H})$, for three coupling elements in which the highest values of reduced stresses were observed, i.e. spring, spring pin and disc input. 


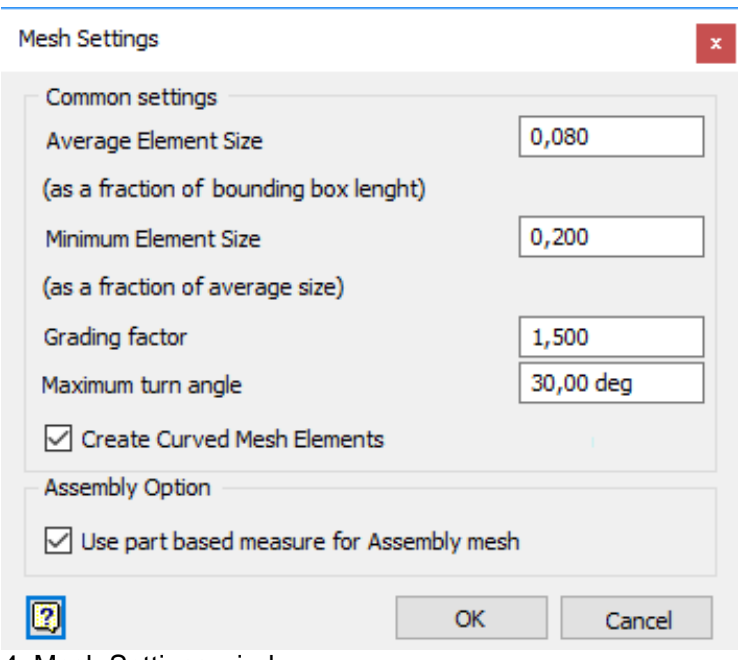

Fig. 4. Mesh Settings window

Convergence Settings

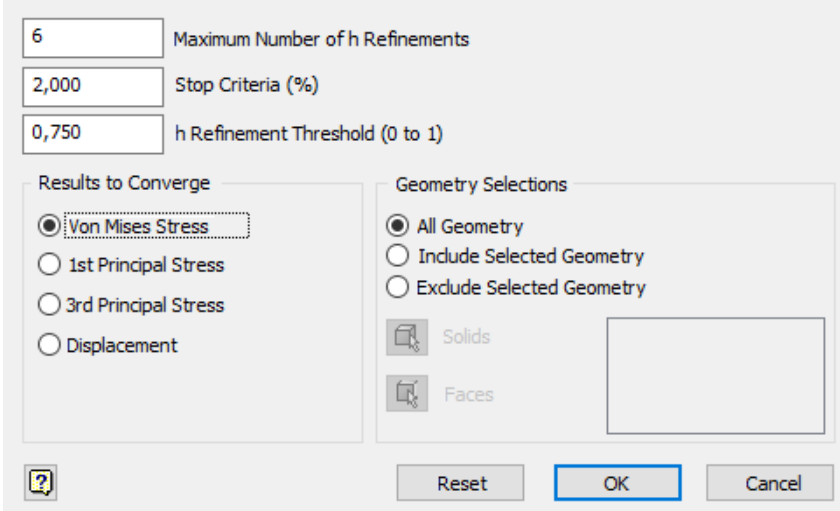

Fig. 5. Convergence Settings window a)

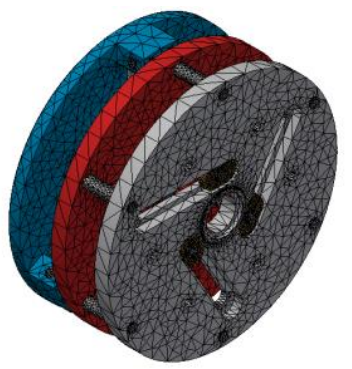

b)

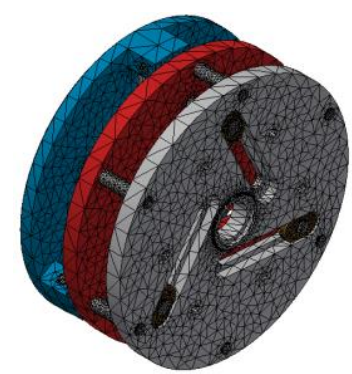

Fig. 6. Mesh of finite elements: a) in position $1, b$ ) in position 2

The highest value of reduced stresses was observed in position 1. In the case of a spring, these stresses amounted to $193.2 \mathrm{MPa}$, for a spring pin - 103.2 MPa, while for the input disk - 46.6 MPa. Significantly lower stresses were obtained in position 2 of the clutch. In the case of the spring and the input disc, the place of maximum reduced stress has changed. In position 1, the maximum value of reduced stresses, calculated according to hypothesis $\mathrm{H}-\mathrm{M}-\mathrm{H}$, occurred on the contact surface with the pin, and in the position 2 - on the contact edge with the input disc. Similarly, there was no entry board. The largest stresses reduced in position 1 occurred on the surface of the hole for the spring pin, while in position 2 - on the contact edge with the spring.

Fig. 10 and 11 show diagrams of convergence of calculations performed for reduced stresses and displacements in positions 1 and 2. Convergence of calculations does not mean that the result is accurate, but that it is independent of the density of the mesh.

In position 1, after preliminary calculations, the system has twice applied smoothing, which consists in increasing the degree of approximation in the element without deflecting the mesh, and one smoothing consisting in the density of the mesh. The difference in stress results reduced between the last two smoothes was $1.912 \%$ and was lower than the assumed retention criterion of $2 \%$. In position 2 , after using two smooths without thickening the mesh, the program made five smooths, compacting the mesh. The difference in the results of stress reduction calculations for the last two steps was also lower than $2 \%$ and amounted to $1.568 \%$. For displacements, these differences were: $0.146 \%$ for position 1 and $0.008 \%$ for position 2 . a)

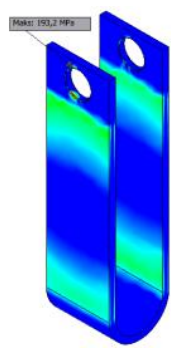

b)

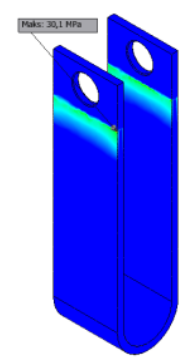

Fig. 7. Distribution of stresses reduced in the spring: a) in position $1, b)$ in position 2 a)

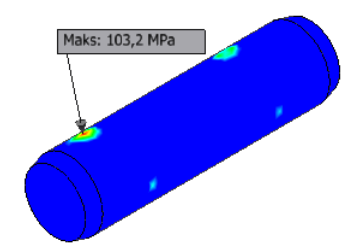

b)

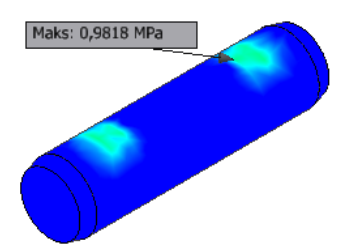

Fig. 8. Distribution of stresses reduced in the pin: a) in position 1, b) in position 2 a)

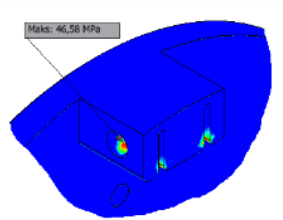

b)

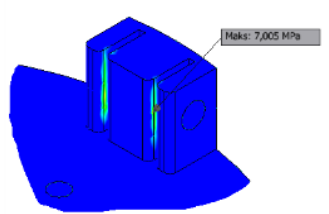

Fig. 9. Distribution of stresses in the input disc: a) in position 1, b) in position 2 a)

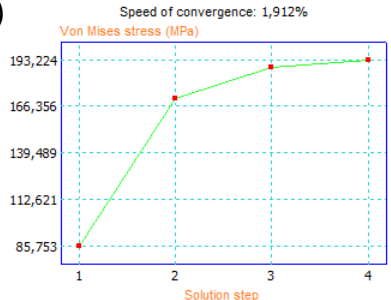

b)

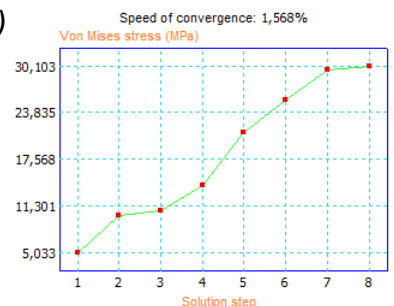

Fig. 10. Plots of convergence of stress reduction calculations for: a) position $1, b)$ position 2 a)

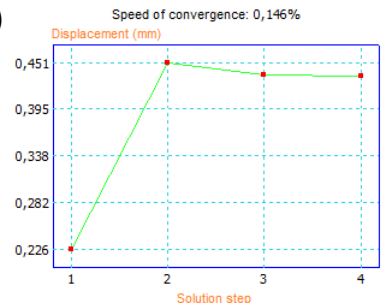

b)

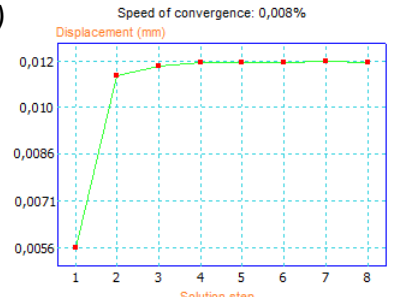

Fig. 11. Convergence graphs of displacement calculations for: a) position 1, b) position 2 
A modal analysis of the clutch spring was also carried out to determine the frequency and form of natural vibrations. The analysis was limited to the first three forms of vibration. In both positions, the surfaces in contact with the input disk and pin as well as the contact edge with the spring bolt were immobilized.

Fig. 12 presents a bar graph with the values of natural frequency, while fig. 13 and fig. 14 show the first three forms of spring vibrations for positions 1 and 2 .

The lowest frequency of spring self-vibrations $-790.2 \mathrm{~Hz}$ - was observed in position 2. The spring bolt then contacts the spring closest to the place of its restraint, and the largest displacement occurs at the free end of the spring. Significantly higher frequencies of the spring's own vibration were observed in position 1. In the case of the first embodiment, which corresponds to the mutual support of one side of the spring, the vibration frequency is $2364.4 \mathrm{~Hz}$, and the largest displacement occurs in the middle part of the other side of the spring.

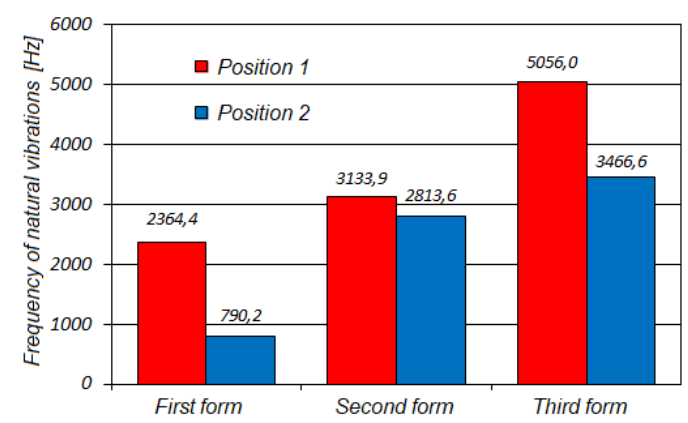

Fig. 12. Natural frequency of the spring in positions 1 and 2 a)

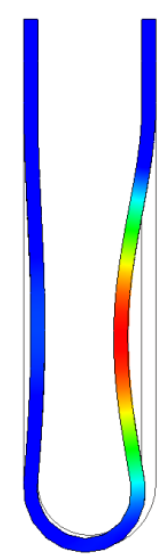

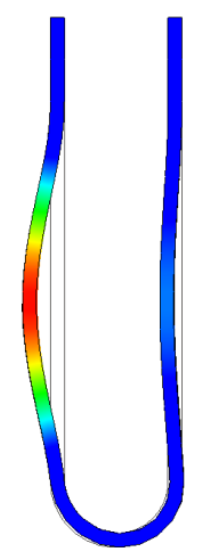

c)

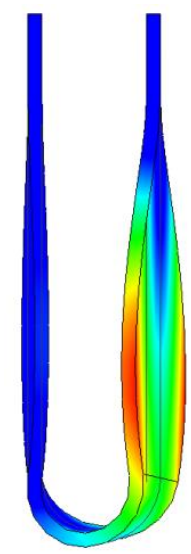

Fig. 13. Forms of the spring's own vibration in position 1: a) the first form, $b$ ) the second form, $c$ ) the third form a)

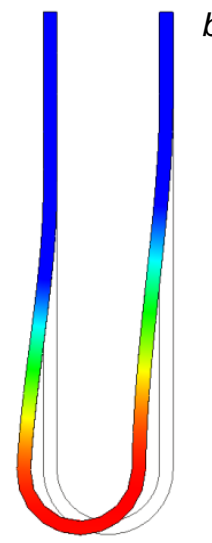

b)

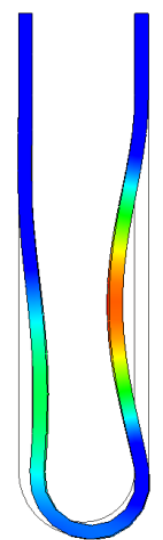

c)

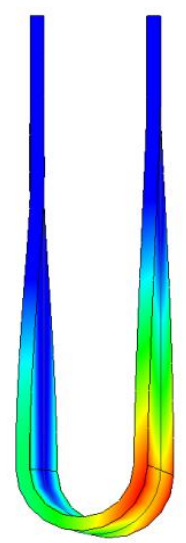

Fig. 14. Forms of the spring's own vibration in position 2: a) the first form, $b$ ) the second form, $c$ ) the third form

\section{Conclusions}

The presented constructional solution of the coupling with the possibility of adjusting torsional flexibility is the development of the concept of using active mechanisms to control and control the vibration level by changing the values of parameters determining the dynamic state of the machine's drive system. The clutch may find application in mechanical systems with the limitation of the level of vibration amplitude in the subcritical region by changing the resonance conditions or in mechanisms that use the resonance state to obtain appropriate operational effects, e.g. in conveyors or vibrating screens or passive beet lifters sugar. Numerical analysis made it possible to determine the frequency and form of natural vibrations as well as to evaluate the effort of selected clutch elements for the constructionally determined dimensions at the load corresponding to the assumed conditions of the mechanism operation. It can be concluded that:

- The maximum value of the reduced stresses in the coupling elements has been observed in position 1, where the maximum clutch flexibility (spring bolts are closest to the free ends of the springs). The reduced stresses of the elements in position 2, in which there is minimal susceptibility (spring bolts are closest to restraint) did not exceed $15.6 \%$ of stress values in position 1 . The greatest reduced stresses were observed in the spring and elements constituting its restraint, i.e. in a pin and an input disk.

- An important stage of simulation research using FEM is to check the convergence of calculations, allowing for the independence of results from mesh density. After calculating the stress values - both in the positions 1 and 2 - the difference in the results between the two last smoothing did not exceed the assumed $2 \%$ criterion.

- The minimum value of natural frequencies obtained on the basis of modal analysis can be used to determine the safe range of rotational speed of the drive system with the clutch with variable torsional flexibility.

- The minimum value of the safety coefficient applied to the yield point exceeds 2 , which confirms the correctness of the clutch structure in terms of strength.

\section{REFERENCES}

1. Homišin J., Kaššay P. "Optimal tuning of torsional oscillating mechanical systems". $54^{\text {th }}$ International Conference of Machine-Design-Departments. Lecture Notes in Mechanical Engineering. (2014): pp. 63-69.

2. Kołodziej P., Boryga M. "Analiza statyczna naprężeń elementów sprzegła z bezstopniową regulacją podatności skrętnej z wykorzystaniem MES". Mechanik. 11 (2017): pp. 1052-1054.

3. Kołodziej P., Boryga M. "Frequency analysis of coupling with adjustable torsional flexibility". Eksploatacja i Niezawodność - Maintenance and Reliability. 16, 2 (2014): pp. 325-329.

4. Monkova K., Monka P., Ondek V. "Modal analysis of lightweight racing car". $2^{\text {nd }}$ International Conference on Computational Modeling, Simulation and Applied Mathematics (CMSAM), DEStech Transactions on Computer Science and Engineering. (2017): pp. 130-134.

5. Pater Z., Tomczak J., Kołodziej P., Boryga M., Gołacki K. Sprzęgło podatne. Patent PL 225230 B1.

6. Stasiak F. "Zbiór ćwiczeń Autodesk ${ }^{\circledR}$ Inventor $^{\circledR}$ 2018. Kurs Professional". ExpertBooks. 2018.

7. Żółtowski M., Liss M., Żółtowski B., Melcer J. "Truss harbor cranes modal design elements research". Polish Maritime Research. 22, 4 (2015): pp. 8492.

Translation of scientific articles, their computer composition and publishing them on the website www.mechanik.media.pl by original articles in Polish is a task financed from the funds of the Ministry of Science and Higher Education designated for dissemination of science.

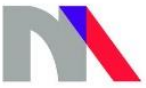

Ministry of Science and Higher Education Republic of Poland 